\title{
Comparative Analysis of Indices of the Metabolic Syndrome in Patients with and without Non-Alcoholic Fatty Liver Disease: A Study in Rajshahi Medical College, Rajshahi, Bangladesh
}

\section{Ahmed Masiha Jamil ${ }^{1 *}$, Rahnuma Shirin ${ }^{2}$, Azizul Hoque ${ }^{3}$, Khalilur Rahman ${ }^{4}$, Mohammad Mahbubur Rahman Khan ${ }^{4}$} Sk. Md. Afzal Uddin ${ }^{1}$

${ }^{1}$ Assistant Professor (Medicine), Rajshahi Medical College, Rajshahi, Bangladesh

${ }^{2}$ Medical Officer, Upazilla Health Complex, Mohonpur, Rajshahi, Bangladesh

${ }^{3}$ Associate Professor (Ex), Medicine, Rajshahi Medical College, Rajshahi, Bangladesh

${ }^{4}$ Professor (Medicine) Rajshahi Medical College, Rajshahi, Bangladesh

Background: Non-Alcoholic fatty liver disease (NAFLD) has become a worldwide health concern with increase in the global incidence of obesity and it is now considered the hepatic component of the metabolic syndrome. As a result of epidemic increase in hypertension, obesity, hypertriglyceridemia along with diabetes mellitus, prevalence of NAFLD and metabolic syndrome have increased globally. Aims and Objective: The study's aim was to compare the indices of the metabolic syndrome in compensated chronic liver disease patients with and without NAFLD at Rajshahi Medical College Hospital, Rajshahi, Bangladesh. Materials and Methods: A total of 91 consecutive patients with compensated chronic liver disease were recruited into the study. A structured questionnaire was administered to obtain relevant socio-demographic data. NAFLD was diagnosed based on clinical, biochemical, ultrasonographic and in a few histological features. The Adult Treatment Panel III criteria were used to identify patients with the metabolic syndrome. Results: Out of ninety one DM patients $2 / 3^{\text {rd }}(67 \%)$ were male and remaining $1 / 3^{\text {rd }}(33 \%)$ were female. Mean age of them was $51.43 \pm 6.24$ years. Among study population $80.2 \%$ were obese, 31.8 were hypertensive and $72.5 \%$ had hypertriglyceridemia. Proportion of NAFLD and metabolic syndrome in T2DM patients was $60.4 \%$ and $61.5 \%$ respectively. $52.7 \%$ had mild whereas $47.3 \%$ had moderate fatty change in liver for persons without NAFLD. The difference was not statistically significant $(\mathrm{p}=0.2)$. In this study demographic variables like BMI, waist circumference were significantly associated with presence of fatty liver in T2DM patients $(\mathrm{p}=0.000$ and $\mathrm{p}=0.000$ respectively). HbA1c was significantly associated with presence of NAFLD ( $p=0.000)$ but ALT, AST and AST: ALT were not significantly associated with presence of NAFLD in T2DM patients $(\mathrm{p}=0.681, \mathrm{p}=0.943$ and $\mathrm{p}=0.749$ respectively). Conclusion: Indices of the metabolic syndrome were more prevalent in persons with NAFLD. It is recommended that patients with NAFLD be screened for metabolic syndrome and appropriate therapy instituted to decrease the risk of both hepatic and cardiovascular complications.

Keywords: Metabolic Syndrome, Non-Alcoholic Fatty Liver Disease, Clinical, Biochemical.

Copyright @ 2020: This is an open-access article distributed under the terms of the Creative Commons Attribution license which permits unrestricted use, distribution, and reproduction in any medium for non-commercial use (NonCommercial, or CC-BY-NC) provided the original author and source are credited.

\section{INTRODUCTION}

Non-alcoholic fatty liver disease (NAFLD) is a condition that is characterised by excess deposition of fat in liver. This ranges from simple steatitis to steatohepatitis, cirrhosis and hepatocellular carcinoma (HCC) [1]. Hypertension, diabetes, obesity and dyslipidemia are predisposing factors of NAFLD [2]. These are also considered as components of metabolic syndrome. NAFLD is supposed to be hepatic manifestation of metabolic syndrome [3, 2, 4]. Patients with NAFLD usually have insulin resistance (IR) which increases lipolysis from the adipose tissue [4], and there is an increased delivery of Free Fatty Acid (FFA) to the liver. These FFA either undergo lipid peroxidation or are esterified with glycerol to form triglycerides, leading to hepatic fat accumulation $[5,6]$. Though the mechanism is unclear by some intricated ways hypertension, central obesity and dyslipidaemia play their role as individual risk factor in the development of NAFLD. Non-alcoholic fatty liver disease (NAFLD) has become a public health problem worldwide due to rising incidence of obesity and Type 2 diabetes [7]. It has emerged as the commonest cause of chronic liver 
disease and abnormal liver function tests among adults in Western countries [3, 2, 4, 26]. The prevalence of Non-alcoholic fatty liver disease (NAFLD) varies in different population of study with a prevalence of $15 \%-$ $30 \%$ in Western populations [8,9] and 9-40\% in Asian countries [1]. The prevalence increases to $58 \%$ in overweight individuals and can be as high as $90 \%$ in obese individuals $[10,11]$. NAFLD is found in $60 \%$ of patients with mixed hyperlipidemia and in $83 \%$ of those with both mixed hyperlipidemia and an elevated serum alanine aminotransferase (ALT) [12, 13]. Non Alcoholic fatty liver disease (NAFLD) is a chronic liver disease which refers to the presence of hepatic steatosis without significant intake of alcohol [43]. A significant alcohol intake is considered as ingestion of $>20 \mathrm{~g} /$ day or $>140 \mathrm{~g} /$ week of alcohol for males and $>10 \mathrm{~g} /$ day or $>70 \mathrm{~g} /$ week of alcohol for females [44]. NAFLD is an asymptomatic disease that can progress to nonalcoholic steatohepatitis (NASH), fibrosis, and cirrhosis and hepatocellular carcinoma [43]. Most patients with this condition are asymptomatic and few present with vague right upper abdominal pain, malaise and fatigue. Others present with abnormal liver function tests or incidental finding of fatty liver on abdominal ultrasound scan for other reasons [45-47]. At present, the global prevalence of NAFLD is estimated at about $9 \%$ in developing countries and $30 \%$ in developed countries [48]. Increasing incidence of NAFLD is reported in Asian countries like Japan and China [14]. There is increased incidence of diabetes, obesity in India in last two decades, it is logical to expect increase in incidence of NAFLD in India $[15,16]$. Bangladesh is the next door neighbour of India and hence supposed to run the same risk. The prevalence of NAFLD in Type 2 DM patients is about 75\% [3], and Diabetes mellitus is observed in $18 \%-45 \%$ NAFLD patients $[12,13]$. Compared with non-diabetic subjects, people with type 2 diabetes appear to have an increased risk of developing NAFLD and have a higher risk of developing fibrosis and cirrhosis [3, 2, 4]. The poor controlled diabetes promotes hepatic steatosis and a vicious cycle binds the two situations. So hepatic steatosis, diabetes, and metabolic syndrome are part of the same disease process ultimately leads to increased morbidity and mortality. Although about $70-75 \%$ of type 2 diabetic patients may have some form of NAFLD [17] precise prevalence of NAFLD in type 2 diabetes is unknown. Some small studies are available that are performed in highly selected populations and some studies have estimated prevalence of abnormal aminotransferase levels only [18-21]. An ultrasonographic study of patients with T2DM showed a $69 \%$ prevalence of NAFLD in Europe [22]. Diabetes as a disease has increased in an alarming way that has created a serious threat to public health globally and also in Bangladesh. We know NAFLD has strong association with diabetes mellitus so prevalence of NAFLD in Diabetes patients is a burning issue in Bangladesh. There is limited data on the prevalence of NAFLD from India [23-25]. Data on prevalence of NAFLD in diabetes patient is still lacking in Bangladesh.

\section{METHODOLOGY}

This was a Cross sectional descriptive study carried out at medicine inpatient and outpatient department, Rajshahi Medical College Hospital, Rajshahi, Bangladesh done from July-2015 to June2017. The study population were adults with type 2 DM attending in Medicine inpatient and outpatient department, Rajshahi Medical College Hospital, Rajshahi, Bangladesh. Sample Size: Ninety one cases of Type 2 DM patients and Purposive sampling method. Dependant and Independent variables: NAFLD, Metabolic syndrome, Age, Sex, Hypertension, BMI, Waist circumference, Duration of DM, Control of DM, Serum TG, Serum HDL cholesterol, Serum LDL cholesterol, Serum Total cholesterol, HbA1c, Serum AST, Serum ALT, AST: ALT and BAAT score.

\section{Inclusion Criteria}

- Patients of both sexes.

- $\quad$ Patients diagnosed as type 2 diabetes mellitus.

\section{Exclusion Criteria}

- Persons with previous history of jaundice.

- Patients with past history of alcohol consumption.

- Persons with history of chronic kidney disease and ischemic heart disease.

- Patients with prior serologic evidence of HBV or HCV infection.

\section{Sample Collection}

Ninety one cases of type 2 DM were included in this study. The diagnosis of type $2 \mathrm{DM}$ was based on performing FBS, PPBS and HbAlc and checking previous treatment records. After meeting the inclusion and exclusion criteria patients with type $2 \mathrm{DM}$ admitted in inpatient department and attending outpatient department of medicine, Rajshahi medical college hospital were included in the study. Age of the patient ranged from 42 to 71 years. Among them 61 were male and 30 were female.

Variables used in this study

\section{Operational Definition NAFLD}

Non-alcoholic fatty liver disease (NAFLD) represents a spectrum of liver disease encompassing simple fatty infiltration (Steatosis), fat and inflammation (non-alcoholic steatohepatitis, NASH) and cirrhosis, in the absence of excessive alcohol consumption (typically a threshold of $<20 \mathrm{~g} /$ day for women and $<30 \mathrm{~g} /$ day for men).

\section{Metabolic Syndrome}

According to the NCEP ATP III definition, metabolic syndrome is present if three or more of the 
following five criteria are met: waist circumference over $90 \mathrm{~cm}$ (men) or $80 \mathrm{~cm}$ (women) for people of Asia pacific region, blood pressure $\geq 130 / 85 \mathrm{~mm} \mathrm{Hg}$, fasting triglyceride (TG) level $\geq 150 \mathrm{mg} / \mathrm{dl}$, fasting high density lipoprotein (HDL) cholesterol level less than $40 \mathrm{mg} / \mathrm{dl}$ (men) or $50 \mathrm{mg} / \mathrm{dl}$ (women) and fasting blood glucose $\geq 110 \mathrm{mg} / \mathrm{dl}$.

\section{Type 2 Diabetes Mellitus}

Type 2 diabetes encompasses individuals who have insulin resistance and usually relative (rather than absolute) insulin deficiency. This form previously referred to as "non-insulin dependent diabetes" or "adult-onset diabetes." It accounts for $90-95 \%$ of all diabetes. Most but not all patients with type 2 diabetes mellitus are obese. Specific aetiologies of type 2 diabetes mellitus are not known.

\section{Procedure of Data Collection Screening and recruitment}

Patients were taken to a separate room where PI introduced himself and explained nature of study. A questionnaire and a written informed consent form (both in Bangla and English) was prepared. Patients were explained the nature of the study. Those who agreed to participate were recruited and detailed consent obtained. Data was obtained by PI from patient using the following methods.

\section{The Scores Are Categorized As Follows}

BMI $\left(\mathrm{kg} / \mathrm{m}^{2}\right): \geq 28=1,<28=0$, Age: $\geq 50=1$, $<50=0$, ALT $(\mathrm{U} / \mathrm{L}): \geq 2$ times rise than normal upper limit $=1,<2$ times rise than normal upper limit $=0$ and serum TG (mg/dl): $\geq 150=1,<150=0$.

\section{Radiological Methodology}

The consultant radiologist in radiology and imaging department, Rajshahi medical college hospital performed $\mathrm{B}$ mode 2 dimensional abdominal Ultrasonography of all recruited patients with PI in attendance. Diagnosis of NAFLD was made on basis of criteria outlined below [20].

\section{Procedure of Data Analysis}

The numerical data obtained from the study was analyzed and the significance of differences was estimated by using statistical methods. After processing of all available information, statistical analysis was performed by using computer based SPSS-16 (Statistical Package for Social Science). Data was expressed in percentage, frequencies mean and standard deviation. Continuous data was expressed as mean \pm standard deviation (SD) and dichotomous data was represented as percentage. Continuous variables were compared through the Student's t-test and for the categorical variables the chi-square test was applied.

\section{RESULTS}

In this study maximum number of patients were in between 46-55 years of age and male female ratio was 2:1. Most of the patients with type $2 \mathrm{DM}$ were nonsmoker (75.0\%), normotensive (68.2\%). 78\% patient were Muslim, 90\% patient were married, $70 \%$ patient had monthly income $>15,000$ taka, 33\% patient were service holder, $33 \%$ patient were housewife and $22 \%$ were businessman, $55 \%$ patient were graduate (Table-1).

Table-1: Socio-demographic distribution of patients with type 2 DM (n=91)

\begin{tabular}{|l|l|l|l|}
\hline & & Frequency & \% \\
\hline Age & S45 years & 6 & 6.5 \\
& 46-55 years & 68 & 75.0 \\
& 56-65 years & 10 & 11.0 \\
& $>65$ years & 7 & 7.5 \\
\hline Sex & Male & 61 & 67.0 \\
& Female & 30 & 33.0 \\
\hline Smoking History & Present & 23 & 25.0 \\
& Absent & 68 & 75.0 \\
\hline Occupation & Service holder & 30 & 33.0 \\
& Businessman & 20 & 22.0 \\
& Housewife & 30 & 33.0 \\
& Others & 11 & 12.0 \\
\hline Religion & Muslim & 71 & 78.0 \\
& Non-Muslim & 20 & 22.0 \\
\hline Education & Below primary & 11 & 12.0 \\
& Up to HSC & 30 & 33.0 \\
& Graduate & 50 & 55.0 \\
\hline Monthly income & $<15000$ Tk. & 27 & 30.0 \\
& $>15000$ Tk. & 64 & 70.0 \\
\hline Marital status & Married & 82 & 90.0 \\
& Unmarried & 9 & 10.0 \\
\hline
\end{tabular}

NB: $\bar{x} \pm$ SD age $=51.43 \pm 6.24$ years 
Table-2: Clinical variables of metabolic syndrome in patients with type 2 DM (n=91)

\begin{tabular}{|l|l|l|l|}
\hline & Frequency & $\%$ & Mean \pm SD \\
\hline BMI & & & \\
\hline Normal $\left(18.5-22.9 \mathrm{~kg} / \mathrm{m}^{2}\right)$ & 1 & 1.1 & $27.27 \pm 2.83$ \\
Overweight $\left(23.0-24.9 \mathrm{~kg} / \mathrm{m}^{2}\right)$ & 17 & 18.7 & \\
Obese $\left(>25.0 \mathrm{~kg} / \mathrm{m}^{2}\right)$ & 73 & 80.2 & \\
\hline Waist circumferance & & & \\
\hline Normal $(<90 \mathrm{~cm}$ in male, $<80 \mathrm{~cm}$ in female) & 32 & 35.2 & $102.22 \pm 8.01$ \\
Increased $(>90 \mathrm{~cm}$ in male, $>80 \mathrm{~cm}$ in female) & 59 & 64.8 & \\
\hline HTN & & & \\
\hline Present & 29 & 31.8 & \\
Absent & 62 & 68.2 & \\
\hline
\end{tabular}

Mean BMI was $27.27 \pm 2.83 \mathrm{~kg} / \mathrm{m}^{2}$, mean WC was $102.22 \pm 8.01 \mathrm{~cm}$. In this study $18.7 \%$ patient was overweight and $80.2 \%$ were obese. Increased WC was observed in $64.8 \%$ patient. In this study mean SBP was
$127.47 \pm 12.72 \mathrm{~mm} \mathrm{Hg}$, mean DBP was $77.09 \pm 10.19$ $\mathrm{mm} \mathrm{Hg}$. $68.2 \%$ study population were normotensive, $31.8 \%$ were hypertensive (Table-2).

Table-3: Investigation findings of patients with type 2 DM $(n=91)$

\begin{tabular}{|l|l|l|l|}
\hline & Frequency & $\%$ & Mean \pm SD \\
\hline HDL & & & \\
\hline Low $(<40 \mathrm{mg} / \mathrm{dl}$ in male, $<50 \mathrm{mg} / \mathrm{dl}$ in female) & 8 & 8.8 & $41.85 \pm 2.72$ \\
Normal $(>40 \mathrm{mg} / \mathrm{dl}$ in male, $>50 \mathrm{mg} / \mathrm{dl}$ in female) & 83 & 91.2 & \\
\hline TG & & & \\
\hline Normal $(<150 \mathrm{mg} / \mathrm{dl})$ & 25 & $27 . .5$ & $186.08 \pm 58.42$ \\
High $(\geq 150 \mathrm{mg} / \mathrm{dl})$ & 66 & 72.5 & \\
\hline
\end{tabular}

In this study only $8.8 \%$ patient was found to have low HDL. $72.5 \%$ patient was found to have high TG, high LDL was found in $26 \%$ patient. Mean total cholesterol was $197.31 \pm 34.10 \mathrm{mg} / \mathrm{dl}$, mean LDL, HDL and TG was $114.18 \pm 35.41 \mathrm{mg} / \mathrm{dl}, 41.85 \pm 2.72 \mathrm{mg} / \mathrm{dl}$, and $186.08 \pm 58.42 \mathrm{mg} / \mathrm{dl}$ respectively (Table-3). Mean AST, ALT, and AST: ALT, serum albumin and serum bilirubin was $29.47 \pm 5.89 \mathrm{U} / \mathrm{L}, 38.09 \pm 5.77 \mathrm{U} / \mathrm{L}, 0.077$ $\pm 0.08,3.80 .22 \mathrm{~g} / \mathrm{dl}$, and $0.45 \pm 0.09 \mathrm{mg} / \mathrm{dl}$ respectively.

Table-4: Components of metabolic syndrome NAFLD in patients with type 2 DM (n=91)

\begin{tabular}{|l|l|l|}
\hline & Frequency & \% \\
\hline Hypertension $(\geq 130 / 85 \mathrm{~mm}$ of $\mathrm{Hg})$ & & 31.8 \\
\hline Present & 29 & 68.2 \\
\hline Absent & 62 & \\
\hline Obesity (evidenced by BMI $\left.>25 \mathrm{~kg} / \mathrm{m}^{2}\right)$ & & 80.2 \\
\hline Present & 73 & 19.8 \\
\hline Absent & 18 & \\
\hline Central obesity (evidenced by waist circumference $>90 \mathrm{~cm}$ in male and >80 cm in female $)$ & & 35.2 \\
\hline Present & 32 & 64.8 \\
\hline Absent & 59 & \\
\hline Hypertriglyceridemia (evidence by TG $\geq 150 \mathrm{mg} / \mathrm{dl})$ & & 27.5 \\
\hline Present & 25 & 72.5 \\
\hline Absent & 66 & \\
\hline Low HDL & & \\
\hline Present & 8 & 8.8 \\
\hline Absent & 83 & 91.2 \\
\hline
\end{tabular}

In this study proportion of hypertension, obesity, central obesity, hypertriglyceridemia and low
HDL were $31.8 \%, 80.2 \%, 35.2 \%, 72.5 \%, 8.8 \%$ respectively (Table-4). 
Table-5: Patient categorization on the basis of single or multiple components of metabolic syndrome in patients with type 2 DM $(n=91)$

\begin{tabular}{|l|l|l|}
\hline Patient categorization & Frequency & \% \\
\hline Type 2 DM with only HTN & 29 & 31.8 \\
\hline Type 2 DM with obesity & 73 & 80.2 \\
\hline Type 2 DM with hypertriglyceridemia and low HDL & 66 & 72.5 \\
\hline Type 2 DM with HTN and obesity & 27 & 29.6 \\
\hline Type 2 DM with obesity, hypertriglyceridemia and low HDL & 61 & 67.03 \\
\hline Type 2 DM with HTN, obesity, hypertriglyceridemia and low HDL & 25 & 27.4 \\
\hline
\end{tabular}

Table-5 shows patient categorization on presence of different components of metabolic syndrome in type $2 \mathrm{DM}$ patients. It revealed $31.8 \%$ patient had type 2 DM with only HTN. $80.2 \%$ patient had type $2 \mathrm{DM}$ with obesity and $72.5 \%$ patient had type 2 DM with hypertriglyceridemia and low HDL. $29.6 \%$ patient had type 2 DM with HTN and obesity, $67.03 \%$ patient had type 2 DM with obesity and hypertriglyceridemia and low HDL where as $27.4 \%$ patient had type 2 DM with HTN, obesity and hypertriglyceridemia and low HDL (Table-5).

Table-6: Duration and control of diabetes mellitus in patients with type 2 DM (n=91)

\begin{tabular}{|l|l|l|l|}
\hline & Frequency & \% & Mean \pm SD \\
\hline Duration of DM & & & \\
\hline 0-4 years & 23 & 25.0 & $7.44 \pm 4.21$ \\
5-9 years & 32 & 35.0 & \\
$>9$ years & 36 & 40.0 & \\
Control of DM & & \multicolumn{1}{|}{} \\
\cline { 1 - 3 } Controlled & 29 & 31.8 & \\
Uncontrolled & 62 & 68.2 & \\
\hline
\end{tabular}

NB: $x \pm$ SD HbA1c was $6.96 \pm 1.17 \%$

In this study $(35.0+40.0) \%$ patients had diabetes more than 5 years and majority $(68.2 \%)$ of patient DM was uncontrolled (Table-6).

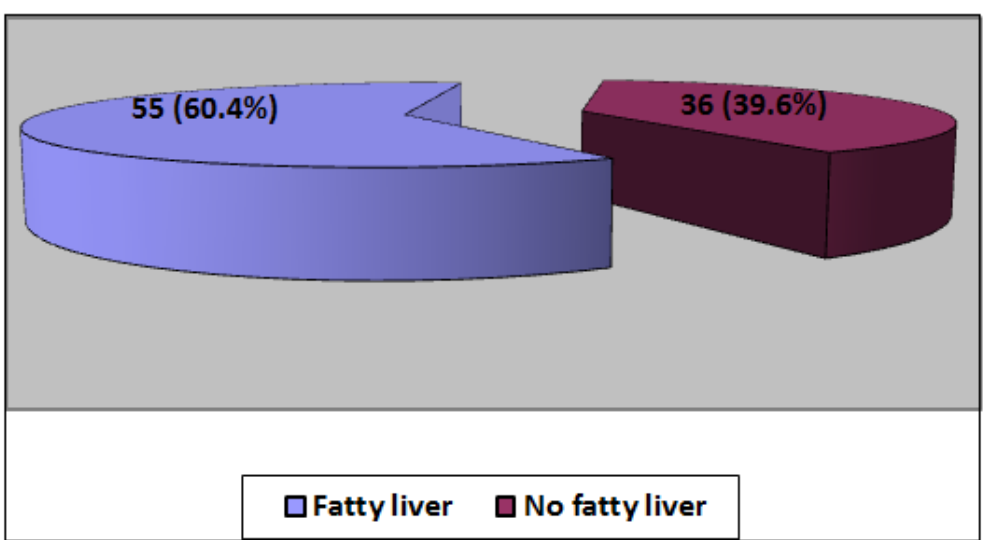

Fig-1: Proportion of fatty liver in patients with type 2 DM by abdominal ultrasonography (n=91)

In this study ultrasonographic proportion of NAFLD was $60.4 \%$ in patients with type 2 DM (Figure-1).

Table-7: Comparison of different clinical variables in diabetic patients with and without fatty liver (n=91)

\begin{tabular}{|l|l|l|l|}
\hline \multirow{2}{*}{ Characteristics } & \multicolumn{2}{|l|}{ Type 2 Diabetes mellitus patients } & T, DF (p) \\
\cline { 2 - 4 } & With fatty liver n=55 (mean \pm SD) & Without fatty liver $\mathbf{n = 3 6}(\mathbf{m e a n} \pm$ SD) & \\
\hline HbA1c & $7.282 \pm 1.26$ & $6.458 \pm 0.78$ & $3.478,89(0.000)$ \\
\hline BMI & $28.48 \pm 2.77$ & $25.40 \pm 1.69$ & $5.97,89(0.000)$ \\
\hline Waist circumference & $103.91 \pm 7.55$ & $99.64 \pm 8.11$ & $2.56,89(0.012)$ \\
\hline ALT & $38.29 \pm 6.10$ & $37.78 \pm 5.28$ & $0.413,89(0.681)$ \\
\hline AST & $29.44 \pm 5.65$ & $29.53 \pm 6.31$ & $-0.072,89(0.943)$ \\
\hline AST:ALT & $0.760 \pm 0.08$ & $0.770 \pm 0.80$ & $-0.32,89(0.749)$ \\
\hline
\end{tabular}


In this study demographic variables like BMI, waist circumference were significantly associated with presence of fatty liver in T2DM patients $(p=0.000$ and $\mathrm{p}=0.000$ respectively). HbA1c was significantly associated with presence of NAFLD $(p=0.000)$ but ALT, AST and AST: ALT were not significantly associated with presence of NAFLD in T2DM patients $(\mathrm{p}=0.681, \mathrm{p}=0.943$ and $\mathrm{p}=0.749$ respectively) (Table-7).

\section{DISCUSSION}

NAFLD has become a worldwide health concern. It was previously thought to be uncommon and usually classified under the cryptogenic causes of chronic liver diseases. It is now recognized that NAFLD results in hepatic metabolic stress damage, and is closely related to insulin resistance (IR) and genetic susceptibility [49, 50]. NAFLD cases among suspected liver disease patients appear to be uncommon in young adults in our environment but common in the fourth decade of life. NAFLD is characterized by fatty infiltration of the liver mostly in the form of triglyceride which exceeds $5 \%$ of the liver weight without a history of significant alcohol intake and not due to other identifiable causes of liver [3]. Fatty liver is a common finding among T2DM individuals. NAFLD and T2DM together have poorer prognosis in terms of higher frequency of cirrhosis and mortality [27]. NAFLD is more commonly seen in T2DM patients and it is now an important public health issue. NAFLD is associated with a variety of features of metabolic syndrome like obesity, hypertension and hypertriglyceridemia and low HDL. NAFLD is the integral part of the metabolic syndrome which comprises a cluster of abnormalities such as hyperglycemia, hypertriglyceridemia and low HDL, hypertension, obesity with insulin resistance as a central pathogenic factor [28]. This cross sectional descriptive study was conducted in medicine department, Rajshahi medical college. This study was designed to determine the ultrasonographic proportion of NAFLD in subjects with T2DM. UIltrasonography has a sensitivity and specificity of $83 \%$ and $100 \%$ respectively as compared with histological finding as the gold standard method in detecting fatty liver [29, 30]. Ultrasonography is a validated tool for screening of NAFLD in the absence of liver biopsy [31-33]. Ninety one patients with T2DM were included in this study who met the inclusion criteria and who were admitted in inpatient or attended outpatient department of medicine in Rajshahi medical college hospital. Out of the five components of metabolic syndrome, diabetes is the risk factor most frequently associated with NAFLD. This study further documented the proportion of the other components of metabolic syndrome namely obesity, elevated blood pressure, elevated triglyceride and low HDL cholesterol and we tried to determine if there was significant association of these factors to NAFLD in study subjects. Liver function tests were also done to asses any derangement. The study population was mostly urban, middle class, living and working in Rajshahi and from diverse occupational background. In this study age range of study population was 42 to 71 years and most study subjects were in between 46-55 years of age. Mean age of the study population $51-43 \pm 6.24$ years. Among ninety one study population sixty one were male and thirty were female. Male female ratio was 2:1. $78 \%$ patient were Muslim, 90\% patient were married, $70 \%$ patient had monthly income $>15,000$ taka, 33\% patient were service holder, $33 \%$ patient were housewife and 22\% were businessman, $55 \%$ patient were graduate. Most of the study population were nonsmoker $(75.0 \%)$, normotensive (68.2\%).In this study mean SBP was $127.47 \pm 12.72 \mathrm{~mm} \mathrm{Hg}$ and mean DBP was $77.09 \pm 10.19 \mathrm{~mm} \mathrm{Hg}$. $18.7 \%$ patient was overweight and increased waist circumferance was observed in $64.8 \%$ patient. Among study population twenty nine patients were hypertensive. Prevalence of HTN in T2DM patient with or without NAFLD was $31.8 \%$. Seventy three T2DM patients were obese. Prevalence of obesity in T2DM patient with or without NAFLD was $80.2 \%$. Sixty six patient had high TG level. So prevalence of hypertriglyceridemia and low HDL as evidenced by high TG level in T2DM patient with or without NAFLD was $72.5 \% .31 .8 \%$ patient had type 2 DM with only HTN. $80.2 \%$ patient had type 2 DM with obesity and $72.5 \%$ patient had type 2 DM with hypertriglyceridemia and low HDL. $29.6 \%$ patient had type 2 DM with HTN and obesity, $67.03 \%$ patient had type $2 \mathrm{DM}$ with obesity and hypertriglyceridemia and low HDL where as $27.4 \%$ patient had type 2 DM with HTN, obesity and hypertriglyceridemia and low HDL. In this study 55 patients out of 91 had ultrasonographic evidence of NAFLD. Proportion of NAFLD in T2DM was $60.4 \%$ in this study by ultrasonography. The diagnosis of NAFLD in the current study was solely based on abdominal ultrasonography. Ultrasonography was considered famous and common clinical procedure to diagnose NAFLD which precisely diagnosed steatosis with a sensitivity of upto $80 \%$ [34, 20,35], found proportion of NAFLD was $61 \%$ among T2DM population detected by abdominal ultrasound which is almost similar to our study and [36], found $60.8 \%$ ultrasonographic occurrence of NAFLD in T2DM patients which was also similar to our study result. This study was found proportion of NAFLD among T2DM patients in their study as $55.68 \%, 56.66 \%, 58.5 \%$, $62 \%, 55.8 \%$ respectively [27]. All these studies were conducted in Bangladesh and neighboring India and the prevalence rate was almost similar to our study. On the other hand [37], found $30.5 \%$ and $10.51 \%$ ultrasonographic presence of NAFLD in T2DM patients which were much lower than our study result. In this study $52.7 \%$ patient had mild fatty change and $47.3 \%$ had moderate fatty changes in liver on ultrasonography. [38], also found 52\% mild and $36 \%$ moderate fatty changes on USG which nearly matched our study. In this study mean age of study population was $51.43 \pm 6.24$ years and mean age of patients in both 
NAFLD and non NAFLD with T2DM patients was $53.24 \pm 6.86$ years and $48.67 \pm 3.81$ years respectively which was statistically significant $(\mathrm{p}=0.000)$. Higher mean age was found by $[38,35]$. Lower age was found by Singh et al., [24]. In this study [38], found no statistically significant difference in age between T2DM patients with and without NAFLD but [35], found significant difference between mean age of two group $(p=0.002)$. In this study, it was found that increased proportion of NAFLD was observed in higher age group but it was not statistically significant $(\mathrm{p}>0.05)$. In this study among study population, majority $(75 \%)$ had diabetes more than 5 years with a mean duration $7.44 \pm 4.21$ years. Longer duration of DM was significantly associated with higher proportion of NAFLD ( $\mathrm{p}<0.01)$. And also found longer duration of DM was significantly associated with increased occurrence of NAFLD $(p<0.001)$ [42]. This study found statistically significant association between increased duration of DM and presence of fatty liver $(\mathrm{p}=0.001, \mathrm{p}<0.001$ and $\mathrm{p}<0.0001$ respectively) [37, 38], and found no significant relationship between duration of DM and presence of fatty liver ( $p=0.45$ and $p=0.81$ respectively). But [27], found mean duration of DM was significantly lower in patients with NAFLD as compared to patient without NAFLD $(p=0.002)$. In this study found most of the study population with NAFLD had prolonged course of DM [39]. Found mean duration of DM was $12 \pm 3$ years among T2DM patient with NAFLD which was statistically significant $(\mathrm{p}<0.001)$ [40]. In this study $68.2 \%$ patient had uncontrolled DM and uncontrolled DM was significantly associated with more severe form of NAFLD $(\mathrm{p}<0.01)$. In this study control of DM was indicated by measurement of HbA1c. Mean HbA1c was $6.96 \pm 1.17 \%$ among study population and HbA1c was $7.282 \pm 1.26 \%$ and $6.45 \pm 0.78 \%$ among NAFLD and non NAFLD patients with T2DM respectively which was statistically significant $(\mathrm{p}=0.000)$. And found control of DM was significantly associated with presence of fatty liver $(p<0.001)$. And found $\mathrm{HbA1c}$ level was significantly higher in diabetic patients with fatty liver in comparison to non-fatty liver diabetic patients $(p<0.0001)$ [37, 41]. But [35], found control of DM was not significantly associated with occurrence of NAFLD in T2DM. FPG and HbA1c statistically did not differ between NAFLD and non NAFLD study population $(\mathrm{p}=0.751$ and $\mathrm{p}=0.064$ respectively). This study showed that the prevalence of impaired glucose tolerance and type 2 diabetic mellitus was significantly higher in participants with NAFLD when compared to non NAFLD patients. Both type 2 DM and NAFLD are associated with adverse outcomes of the other; Type $2 \mathrm{DM}$ is a risk factor for progressive liver disease and liver-related death in patients with NAFLD, whereas NAFLD may be a predictor of cardiovascular risk and mortality in individuals with T2DM [51]. The characteristic findings in NAFLD include increased cholesterol (VLDL and LDL), increased triglyceride and low HDL [52]. This was essentially the same pattern seen in this study. There was also increased triglyceride levels in the NAFLD group due to over production of VLDL particles during lipid metabolism associated with insulin resistance. In the blood, the TG content of VLDL is progressively reduced by the action of lipoprotein lipase eventually resulting in intermediate density lipoproteins and LDL with high cholesterol content [50]. The prevalence of hypertension was significantly higher in NAFLD when compared to non NAFLD subjects and was similar to findings from other studies $[47,48]$.

\section{CONCLUSION}

Indices of the metabolic syndrome were more prevalent in patients with NAFLD. It is recommended that patients with NAFLD be screened for metabolic syndrome and appropriate therapy instituted to decrease the risk of both hepatic and cardiovascular complications.

\section{REFERENCES}

1. Farrell GC, Larter CZ. Nonalcoholic fatty liver disease: from steatosis to cirrhosis. Hepatology. 2006 Feb;43(S1):S99-112.

2. McCullough AJ. Thiazolidinediones for nonalcoholic steatohepatitis-promising but not ready for prime time. New England Journal Med, 2006;355(22):2361-3.

3. Angulo P. Nonalcoholic fatty liver disease. New England Journal of Medicine. 2002 Apr 18;346(16):1221-31.

4. Marchesini G, Marzocchi R, Agostini F, Bugianesi E. Nonalcoholic fatty liver disease and the metabolic syndrome. Current opinion in lipidology. 2005 Aug 1;16(4):421-7.

5. Feldstein AE, Werneburg NW, Canbay A, Guicciardi ME, Bronk SF, Rydzewski R, Burgart LJ, Gores GJ. Free fatty acids promote hepatic lipotoxicity by stimulating TNF- $\alpha$ expression via a lysosomal pathway. Hepatology. 2004 Jul;40(1):185-94.

6. Yamaguchi K, Yang L, McCall S, Huang J, Yu XX, Pandey SK, Bhanot S, Monia BP, Li YX, Diehl AM. Inhibiting triglyceride synthesis improves hepatic steatosis but exacerbates liver damage and fibrosis in obese mice with nonalcoholic steatohepatitis. Hepatology. 2007 Jun;45(6):1366-74..

7. Yoon KH, Lee JH, Kim JW, Cho JH, Choi YH, Ko SH, Zimmet P, Son HY. Epidemic obesity and type 2 diabetes in Asia. The Lancet. 2006 Nov 11;368(9548):1681-8.

8. Bedogni G, Miglioli L, Masutti F, Tiribelli C, Marchesini G, Bellentani S. Prevalence of and risk factors for nonalcoholic fatty liver disease: the Dionysos nutrition and liver study. Hepatology. 2005 Jul;42(1):44-52.

9. de Oliveira CP, de Mello ES, Alves VA, Saviero SM, Strauss E. Changes in histological criteria lead to different prevalences of nonalcoholic 
steatohepatitis in severe obesity. Annals of hepatology. 2007;6(4):255-61.

10. Boza C, Riquelme A, Ibañez L, Duarte I, Norero E, Viviani P, Soza A, Fernandez JI, Raddatz A, Guzman S, Arrese M. Predictors of nonalcoholic steatohepatitis (NASH) in obese patients undergoing gastric bypass. Obesity surgery. 2005 Sep 1;15(8):1148-53.

11. Harnois F, Msika S, Sabaté JM, Mechler C, Jouet P, Barge J, Coffin B. Prevalence and predictive factors of non-alcoholic steatohepatitis (NASH) in morbidly obese patients undergoing bariatric surgery. Obesity surgery. 2006 Feb 1;16(2):183-8.

12. Browning JD, Szczepaniak LS, Dobbins R, Nuremberg P, Horton JD, Cohen JC, Grundy SM, Hobbs HH. Prevalence of hepatic steatosis in an urban population in the United States: impact of ethnicity. Hepatology. 2004 Dec;40(6):1387-95.

13. Browning JD. Statins and hepatic steatosis: perspectives from the Dallas Heart Study. Hepatology. 2006 Aug;44(2):466-71.

14. Amarapurkar D, Kamani P, Patel N, Gupte P, Kumar P, Agal S, Baijal R, Lala S, Chaudhary D, Deshpande A. Prevalence of non-alcoholic fatty liver disease: population based study. Annals of hepatology. 2007 Jul 1;6(3):161-3.

15. Mohan V, Deepa R. Adipocytokines and the expanding'Asian Indian Phenotype'. The Journal of the Association of Physicians of India. 2006 Sep 1;54:685-6.

16. Misra A, Vikram NK. Insulin resistance syndrome (metabolic syndrome) and Asian Indians. Current Science. 2002 Dec 25:1483-96.

17. Medina J, Fernández-Salazar LI, García-Buey L, Moreno-Otero R. Approach to the pathogenesis and treatment of nonalcoholic steatohepatitis. Diabetes care. 2004 Aug 1;27(8):2057-66.

18. Jick SS, Stender M, Myers MW. Frequency of liver disease in type 2 diabetic patients treated with oral antidiabetic agents. Diabetes Care. 1999 Dec 1;22(12):2067-71.

19. Erbey JR, Silberman C, Lydick E. Prevalence of abnormal serum alanine aminotransferase levels in obese patients and patients with type 2 diabetes. The American journal of medicine. 2000 Nov 1;109(7):588-90.

20. Younossi ZM, Gramlich T, Matteoni CA, Boparai $\mathrm{N}$, McCullough AJ. Nonalcoholic fatty liver disease in patients with type 2 diabetes. Clinical Gastroenterology and Hepatology. 2004 Mar $1 ; 2(3): 262-5$.

21. Jimba S, Nakagami T, Takahashi M, Wakamatsu T, Hirota Y, Iwamoto Y, Wasada T. Prevalence of non-alcoholic fatty liver disease and its association with impaired glucose metabolism in Japanese adults. Diabetic Medicine. 2005 Sep;22(9):1141-5.

22. Leite NC, Salles GF, Araujo AL, Villela-Nogueira $\mathrm{CA}$, Cardoso CR. Prevalence and associated factors of non-alcoholic fatty liver disease in patients with type-2 diabetes mellitus. Liver international. 2009 Jan;29(1):113-9.

23. Singh SP, Nayak S, Swain M, Rout N, Mallik RN, Agrawal O, Meher C, Rao MV. Prevalence of nonalcoholic fatty liver disease in coastal eastern India: a preliminary ultrasonographic survey. Tropical gastroenterology: official journal of the Digestive Diseases Foundation. 2004;25(2):76-9.

24. Singh SP, Singh A, Pati GK, Misra B, Misra D, Kar SK, Panigrahi MK, Meher C, Agrawal O, Rout N, Pattnaik K. A study of prevalence of diabetes and prediabetes in patients of nonalcoholic fatty liver disease and the impact of diabetes on liver histology in coastal eastern India. Journal of Diabetes Mellitus. 2014 Oct 16;4(04):290-296.

25. Duseja A, Chawla Y. Nonalcoholic fatty liver disease in India--how much? How soon?. Tropical gastroenterology: official journal of the Digestive Diseases Foundation. 2005;26(1):1.

26. Bellentani S, Marino M. Epidemiology and natural history of non-alcoholic fatty liver disease (NAFLD). Ann Hepatol; 2009; 8:S4-S8.

27. Merat S, Yarahmadi S, Tahaghoghi S, Alizadeh Z, Sedighi N, Mansournia N, Ghorbani A, Malekzadeh R. Prevalence of fatty liver disease among type 2 diabetes mellitus patients and its relation to insulin resistance. Middle East Journal of Digestive Diseases (MEJDD). 2009;1(2):74-9.

28. Viswanathan V, Kadiri M, Medimpudi S, Kumpatla S. Association of non-alcoholic fatty liver disease with diabetic microvascular and macrovascular complications in South Indian diabetic subjects. International Journal of Diabetes in Developing Countries. 2010 Oct 1;30(4):30227.

29. Osawa H, Mori Y. Sonographic diagnosis of fatty liver using a histogram technique that compares liver and renal cortical echo amplitudes. Journal of clinical ultrasound. 1996 Jan;24(1):25-9.

30. Saverymuttu SH, Joseph AE, Maxwell JD. Ultrasound scanning in the detection of hepatic fibrosis and steatosis. Br Med J (Clin Res Ed). 1986 Jan 4;292(6512):13-5.

31. Contos MJ, Sanyal AJ. The clinicopathologic spectrum and management of nonalcoholic fatty liver disease. Advances in anatomic pathology. 2002 Jan 1;9(1):37-51.

32. Lonardo A, Bellini M, Tartoni P, Tondelli E. The bright liver syndrome. Prevalence and determinants of a" bright" liver echopattern. Italian journal of gastroenterology and hepatology. 1997 Aug;29(4):351-6.

33. Tominaga K, Kurata JH, Chen YK, Fujimoto E, Miyagawa S, Abe I, Kusano Y. Prevalence of fatty liver in Japanese children and relationship to obesity. Digestive diseases and sciences. 1995 Sep 1;40(9):2002-9.

34. Cho CS, Curran S, Schwartz LH, Kooby DA, Klimstra DS, Shia J, Munoz A, Fong Y, Jarnagin 
Ahmed Masiha Jamil et al., SAS J Med, Feb, 2020; 6(2): 38-46

WR, DeMatteo RP, Blumgart LH. Preoperative radiographic assessment of hepatic steatosis with histologic correlation. Journal of the American College of Surgeons. 2008 Mar 1;206(3):480-8.

35. Sibia RS, Dhoot S, Sibia P, Murarka S, Bhardwaj $\mathrm{H}$, Aggarwal AD. Prevalence of nonalcoholic fatty liver disease in patients with type 2 diabtes and its correlation with coronary risk factors. National journal of laboratory medicine; 2016;5(4): 10111013.

36. Luxmi S, Sattar RA, Ara J. Association of nonalcoholic fatty liver with type 2 diabetes mellitus. Jlumhs. 2008 Sep;9:188-93.

37. Sharavanan TK, Premalatha E. Prevalence of nonalcoholic fatty liver disease in type 2 diabetes mellitus patients in a rural health care hospital. Sch J Appl Med Sci. 2015 Aug;3:1834-7.

38. Rao SV, Sikariya KK. Prevalence and risk factors of nonalcoholic fatty liver disease in type 2 diabetes mellitus in a tertiary care centre in Western India. IOSR Journal of Dental and Medical Sciences. 2016;15(2):1-7.

39. Bakalov D, Boyanov M, Sheinkova G, Vezenkova L, Prodanova G, Christov V. Non-alcoholic fatty liver disease (NAFLD) in men with Type 2 diabetes. J Clin Med. 2010;3(31): 31-35.

40. Targher G, Bertolini L, Padovani R, Rodella S, Tessari R, Zenari L, Day C, Arcaro G. Prevalence of nonalcoholic fatty liver disease and its association with cardiovascular disease among type 2 diabetic patients. Diabetes care. 2007 May 1;30(5):1212-8.

41. Somalwar AM, Raut AD. Study of association of non alcoholic fatty liver disease (NAFLD) with micro and macrovascular complications of type 2 diabetes mellitus (T2DM). Int J Res Med Sci. 2014 May;2(2):493-7.

42. Jali MV, Kambar S, Jali SM, Hiremath MB. Prevalence of non-alcoholic fatty liver disease among type-2diabetes mellitus patients-a crosssectional hospital-based study. Al Ameen J Med Sci. 2015;8(1):50-4.

43. Caldwell S, Argo C. The natural history of nonalcoholic fatty liver disease. Dig Dis. 2010; 28:162-168.
44. Loria P, Adinolfi LE, Bellentani S, Bugianesi E, Grieco A, Fargion S, Gasbarrini A, Loguercio C, Lonardo A, Marchesini G, Marra F. Practice guidelines for the diagnosis and management of nonalcoholic fatty liver disease: A decalogue from the Italian Association for the Study of the Liver (AISF) Expert Committee. Digestive and Liver Disease. 2010 Apr 1;42(4):272-82.

45. Liao XH, Cao X, Liu J, Xie XH, Sun YH and Zhong BH. Prevalence and features of fatty liver detected by physical examination in Guangzhou. World J Gastroenterol, 2013; 19:5334-5339.

46. Suzuki A, Angulo P, Lymp J, St. Sauver J, Muto A, Okada T, Lindor K. Chronological development of elevated aminotransferases in a nonalcoholic population. Hepatology. 2005 Jan;41(1):64-71.

47. Gomercic M, Duvnjak M, Barsic N. Ultrasonography in the diagnosis of non alcoholic fatty liver disease. Acta Med Croatica, 2009; 63 (Suppl 3):1-3.

48. Younossi Z, Quentin M and Bugianesi AE. Global burden of NAFLD and NASH: trends, predictions, risk factors and prevention. Nature Reviews; Gastroenterology and Hepatology, 2018; 15:11-20.

49. Sanyal AJ, Campbell-Sargent C, Mirshahi F, Rizzo WB, Contos MJ, Sterling RK, Luketic VA, Shiffman ML, Clore JN. Nonalcoholic steatohepatitis: association of insulin resistance and mitochondrial abnormalities. Gastroenterology. 2001 Apr 1;120(5):1183-92.

50. Larter CZ, Chitturi S, Heydet D, Farrell GC. A fresh look at NASH pathogenesis. Part 1: the metabolic movers. J Gastroenterol Hepatol, 2010; 25:672-690.

51. Galassi A, Reynold K, He J. Metabolic syndrome and risk of cardiovascular disease: a meta-analysis. Am J Med, 2006; 119(10): 812-819.

52. Onpan C, Ashwani K, Pumet P, Sakita S, Velimir A, Carol C. The impact of fat distribution on the severity of NAFLD and metabolic syndrome. Hepatology, 2007; 46(4): 1091-1100. 